\title{
Detection of Endogenous DNA Double-strand Breaks in Oral Squamous Epithelial Lesions by P53-binding Protein 1
}

\author{
TOSHINOBU IMAIZUMI ${ }^{1,2}$, KATSUYA MATSUDA $^{1}$, KEI TANAKA $^{2}$, HISAYOSHI KONDO $^{3}$, \\ NOZOMI UEKI ${ }^{1}$, HIROKAZU KUROHAMA ${ }^{1}$, CHIEKO OTSUBO ${ }^{1}$, \\ YUKI MATSUOKA ${ }^{1}$, YUKO AKAZAWA ${ }^{1}$, SHIRO MIURA ${ }^{4}$ and MASAHIRO NAKASHIMA ${ }^{1}$ \\ ${ }^{1}$ Department of Tumor and Diagnostic Pathology, Atomic Bomb Disease Institute, \\ Nagasaki University Graduate School of Biomedical Sciences, Nagasaki, Japan; \\ ${ }^{2}$ Department of Diagnostic Pathology, Nagasaki University Hospital, Nagasaki, Japan; \\ ${ }^{3}$ Biostatistics Section, Division of Scientific Data Registry, \\ Atomic Bomb Disease Institute, Nagasaki University, Nagasaki, Japan; \\ ${ }^{4}$ Department of Diagnostic Pathology, National Hospital Organization Nagasaki Medical Center, Nagasaki, Japan
}

\begin{abstract}
Background/Aim: P53-binding protein 1 (53BP1) is one of the DNA damage response (DDR) molecules. This study aimed to assess 53BP1 expression by immunofluorescence (IF) as a biomarker to differentiate between oral squamous epithelial lesions (OSELs). Materials and Methods: We analyzed 129 archival oral biopsy samples, including 18 benign squamous lesions (BSLs), 37 low-grade dysplasias (LGDs), 22 high-grade dysplasias (HGDs), and 52 oral squamous cell carcinomas (OSCCS). 53BPI and Ki-67 expressions were examined by double IF to assess the type of 53BP1 expression. Results: We found that OSCC exhibited several 53BP1 nuclear foci, particularly high-DNA damage response (HDDR) and large focus (LF)-type, suggesting the presence of endogenous DNA double-strand breaks in the cancer genome, which could disrupt DDR and induce genomic injury. We also found a difference in 53BP1 expression between $L G D$ and HGD, but not between BSL and LGD. Among the Ki-67-positive cells, HDDRand LF-type expressions were higher in OSELs of higher grades. Conclusion: 53BP1 expression can be a valuable biomarker for OSELs to help estimate the grade of oral epithelial dysplasia.
\end{abstract}

This article is freely accessible online.

Correspondence to: Masahiro Nakashima, MD, Ph.D., Department of Tumor and Diagnostic Pathology, Atomic Bomb Disease Institute, Nagasaki University Graduate School of Biomedical Sciences, 1-12-4 Sakamoto, Nagasaki 852-8523, Japan. Tel: +81 958197105, Fax: +81958197108, e-mail: moemoe@nagasakiu.ac.jp

Key Words: 53BP1, genome instability, immunofluorescence, oral cancer, tumor biomarkers.
Oral squamous cell carcinoma (OSCC) incidence is estimated to be more than 500,000 annually (1). It is commonly preceded by oral epithelial dysplasia (OED), and its 5-year survival rate can be improved by early-stage diagnosis (2). The $4^{\text {th }}$ edition of the WHO Classification of Head and Neck Tumours (2017) defines OED as 'a spectrum of architectural and cytological epithelial changes caused by accumulation of genetic changes associated with an increased risk of progression to squamous cell carcinoma (SCC) (3). However, dysplasia grading is poorly reproducible between pathologists. Although OED is traditionally divided into three severity grades, a binary system is also advocated to improve reproducibility. Consensus grading after reviewing by multiple pathologists may enhance diagnostic reliability. The Japanese Society of Oral Oncology recommends a binary system, such as lowgrade and high-grade dysplasia (LGD and HGD), to diagnose OED based on clinical management (4). HGD may include carcinoma in situ, and commonly develop into SCC, hence HGD lesions are usually recommended for active surgical intervention (5). Most LGDs never progress to carcinoma, so a 'wait and see' policy may be adopted for these lesions. Thus, the clinical management of OED is dependent on the histopathological diagnosis by biopsy.

Histological findings of architectural and cytological disturbances in biopsy specimens are critical for OED diagnosis. However, there is lack of consistent evidence to indicate translation of individual features into a dysplasia grade. Thus, the issue of poor consensus is based on the current diagnostic criteria underlying the low reproducibility of OED differential diagnosis and necessitates establishment of an ancillary technique to diagnose OED. P53-binding protein 1 (53BP1) is a DNA damage response (DDR) molecule with a BRCA1 C-terminal domain (6). 53BP1 
rapidly forms nuclear foci (NF) with other DDR molecules, like ATM and $\gamma \mathrm{H} 2 \mathrm{AX}$, at the site of DNA double-strand breaks (DSBs) in response to ionizing radiation $(7,8)$. Our previous dual-color immunofluorescence (IF) analysis revealed frequent co-localization of 53BP1 and $\gamma \mathrm{H} 2 \mathrm{AX} \mathrm{NF}$, consistent with DNA DSBs induction in irradiated rat thyroid follicular cells (9). Additionally, we demonstrated the frequent co-localization of 53BP1 and $\gamma \mathrm{H} 2 \mathrm{AX} \mathrm{NF}$ in untreated human thyroid follicular carcinomas, suggesting occurrence of endogenous DNA DSBs and DDR activation as hallmarks of tumor genome instability (9). Furthermore, we previously demonstrated that the number of 53BP1 NF in uterine cervical cells appeared to increase with cancer progression (10). The distribution of 53BP1 NF was similar to that of punctate human papilloma virus (HPV) signals as determined by in situ hybridization (ISH) and also to the pattern of $\mathrm{p} 16^{\mathrm{INK} 4 \mathrm{a}}$ overexpression, an established surrogate marker for HPV infection in cervical squamous intraepithelial lesions (SILs) (10). Thus, 53BP1 NF are associated with viral infection and replication stress, and the IF analysis of 53BP1 expression can be a useful tool to estimate the grade of SIL during cervical carcinogenesis (10). We hypothesize that the expression of 53BP1 may be an indicator of an endogenous genomic instability that drives tumorigenesis. This study aimed to evaluate type of 53BP1 expression as an indicator of genomic instability in oral squamous epithelial lesion.

\section{Materials and Methods}

Patients and histological evaluation. We found total 158 biopsy cases of oral lesions which were diagnosed as mild $(n=62) /$ moderate $(n=23) /$ severe $(n=12)$ dysplasia and SCC $(n=61)$ at the Nagasaki University Hospital between 2016 and 2017. Pathological diagnosis was confirmed by two certified pathologists (S.M. and M.N.) according to the $4^{\text {th }}$ WHO Classification of Head and Neck Tumours (Figure 1) (3). OED dysplasia grading was performed using the binary system (LGD or HGD). All samples were formalin-fixed and paraffin-embedded tissues that were prepared for IF, immunohistochemistry (IHC), and fluorescence in situ hybridization (FISH) studies. This study was performed retrospectively in accordance with the tenets of the Declaration of Helsinki. The Ethics Committee of Nagasaki University approved the study (approval date: August 27, 2020; \#15062617-4) and waived the need for informed consent. All methods were carried out in accordance with relevant guidelines and regulations. Patient profiles were anonymized by coding and collectively summarized with the obtained data as the final dataset. Patients were able to opt out of the study by following the instructions provided on the institute website.

IF analysis of 53BP1 expression. 53BP1 expression was examined with Ki-67 expression by double IF analysis to assess the extent and integrity of DDR. After antigen retrieval via microwave treatment in Target Retrieval Solution, Citrate pH 6 (Agilent Technologies, Santa Clara, CA, USA), deparaffinized sections were preincubated with Dako Protein Block, Serum-Free (DakoCytomation, Glostrup, Denmark), then incubated with polyclonal rabbit anti-53BP1 antibody (1:1,000; Bethyl Laboratories, Montgomery, TX, USA), and monoclonal mouse anti-Ki-67 antibody (clone MIB-1; 1:50; DakoCytomation). The samples were then incubated with Alexa Fluor ${ }^{\circledR}$ 488-conjugated goat anti-rabbit and Alexa Fluor ${ }^{\circledR}$ 546conjugated goat anti-mouse antibodies (1:2,000; Invitrogen, Carlsbad, CA, USA), and mounted using VECTASHIELD ${ }^{\circledR}$ HardSet $^{\mathrm{TM}}$ Mounting Medium with DAPI (Vector Laboratories, Burlingame, CA, USA). The stained sections (minimum 25-30 slices per field) were photographed at 1,000-fold magnification using the Z-stack function on a High Standard All-in-One Fluorescence Microscope (Biorevo BZ-X710; KEYENCE, Osaka, Japan), which enabled the delineation of all 53BP1 NF in the nucleus. The 53BP1 signals were measured using the image analysis software provided with the Biorevo BZ-X710 microscope. 53BP1 immunoreactivity type was classified as: i) stable (no staining), ii) low DDR (LDDR; 1 or 2 discrete NF, $<1.0 \mu \mathrm{m}$ ), iii) high DDR (HDDR; 3 or more discrete NF, $<1.0 \mu \mathrm{m}$, or diffuse nuclear staining), or iv) large foci (LF; discrete NF, $\geq 1.0 \mu \mathrm{m}$ ). Each type was categorized as either Ki-67 negative or positive, yielding eight categories (Figure 2). The percentage of nuclei with each type of 53BP1 immunoreactivity was calculated in at least five consecutive fields along the basement membrane of each squamous lesion.

IHC for p53 and p16 INK4a expression. Deparaffinized 4- $\mu \mathrm{m}$ sections were pre-treated by heating in a microwave in a $\mathrm{pH} 9.0$ phosphate buffer for $20 \mathrm{~min}$, then incubated with anti-p53 monoclonal antibody (1:200; Leica Biosystems, Nussloch, Germany) or mouse anti-p16 INK4a monoclonal antibody (1:2; Roche Diagnostics, Basel, Switzerland) for $15 \mathrm{~min}$ at $37^{\circ} \mathrm{C}$. After incubation for $8 \mathrm{~min}$ with the primary reagent of the Bond polymer system (Leica Biosystems), the samples were reacted with the polymer reagent (peroxidase-labelled polymer-conjugated anti-mouse polyclonal antibody and anti-rabbit polyclonal antibody) for $8 \mathrm{~min}$. All samples were then incubated with 3,3,-diaminobenzidine hydrogen peroxide for $10 \mathrm{~min}$ and counterstained with hematoxylin. The squamous epithelial lesions were considered positive for 53BP1 if nuclear staining from the basal side was $\geq 50 \%$. The level of p16 INK4a immunoreactivity was evaluated according to the following criteria: no staining, focal nuclear and cytoplasmic staining, or diffuse and intense nuclear and cytoplasmic staining.

Dual-color FISH analysis of the 9p21 locus. To evaluate the association between $\mathrm{p} 16^{\mathrm{INK} 4 \mathrm{a}}$ immunoreactivity and loss of the p16 INK4a gene, dual-color FISH with Vysis LSI CDKN2A SpectrumOrange/CEP9 SpectrumGreen Probes (Abbott, Chicago, IL, USA) and a Histra FISH pre-treatment kit (Jokoh, Tokyo, Japan) was carried out according to the manufacturers' instructions. FISH analysis was performed for 5 BSL cases, which included 2 samples negative and 3 samples diffusely positive for $\mathrm{p} 16^{\mathrm{INK}} 4 \mathrm{a}$ by IHC, and 10 SCC cases, including 5 samples each of negative and positive p16 $6^{\text {INK4a }}$ by IHC. Briefly, after deparaffinization and microwave treatment in pre-treatment solution for $20 \mathrm{~min}$ at $94^{\circ} \mathrm{C}, 4-\mu \mathrm{m}$ tissue sections were pre-digested with $0.06 \%$ protease for $45 \mathrm{~min}$ at $39^{\circ} \mathrm{C}$. The tissue sections were denatured with FISH probes at $74^{\circ} \mathrm{C}$ for 2 min, and subsequently incubated at $37^{\circ} \mathrm{C}$ for $16 \mathrm{~h}$. The sections were washed in $50 \%$ formamide and $2 \times$ standard saline citrate, followed by counterstaining with 4',6-diamidino-2-phenylindole. FISH signals were automatically analyzed by a fluorescence microscope 


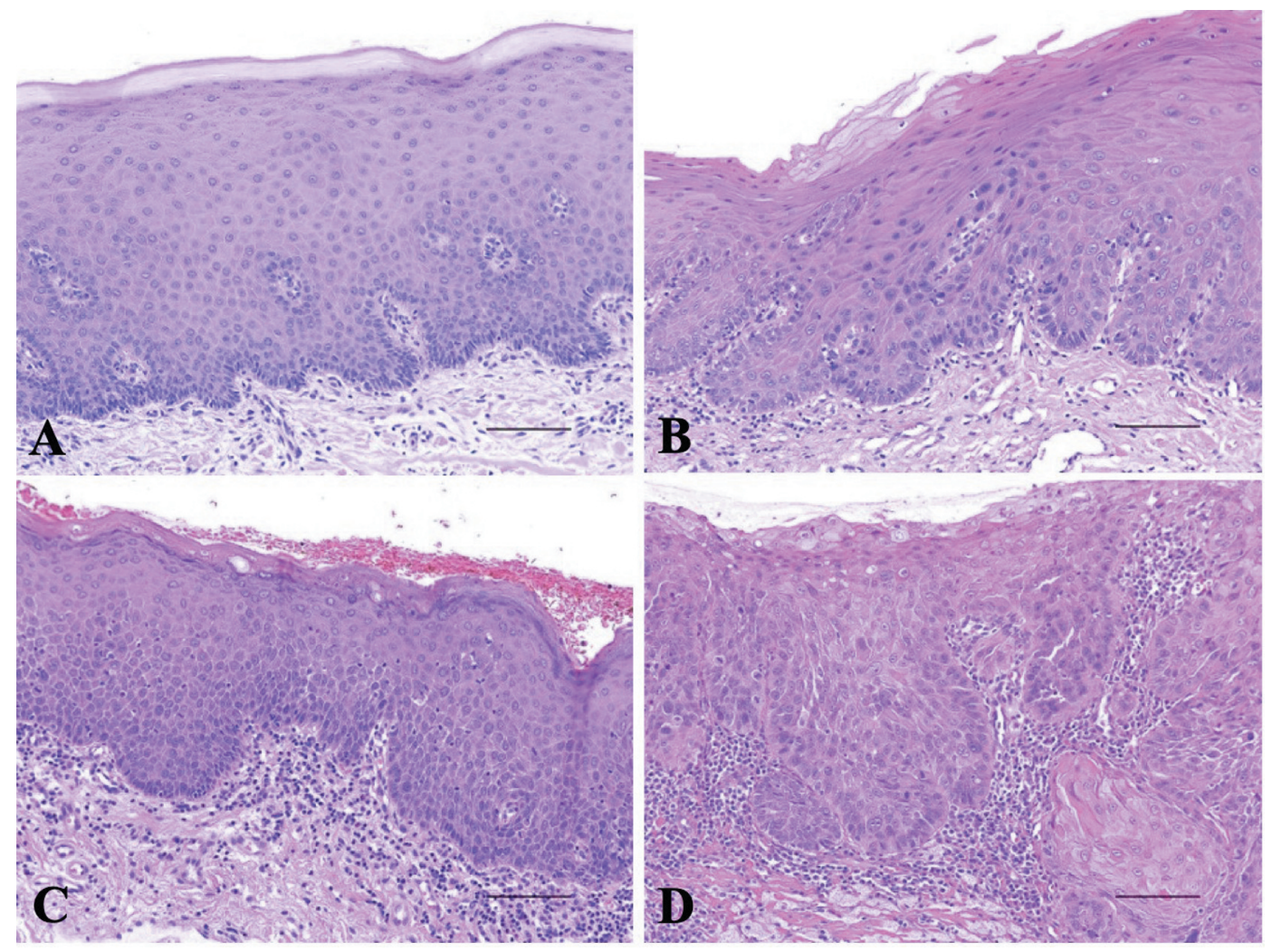

Figure 1. Representative histological images of oral epithelial lesions. (A) Benign squamous lesion. (B) Low-grade dysplasia. (C) High-grade dysplasia. (D) Oral squamous cell carcinoma. The scale bars indicate $100 \mu \mathrm{m}$.

(OLYMPUS BX63, Olympus, Tokyo, Japan) with the image analysis software Bioview DUET ${ }^{\text {TM }}$ IFU (Bioview, Rehovot, Israel).

Statistical analysis. We assessed associations between histological type of an oral squamous epithelial lesion, type of 53BP1 expression, and level of p16 INK4a and p53 immunoreactivity with the Jonckheere-Terpstra, Cochran-Armitage, and $t$-tests. A logistic regression model and receiver operating characteristic (ROC) curve were used to evaluate the significance of 53BP1 expression using IF as a diagnostic test to differentiate HGD and OSCC. The closest distance from the top left corner (point $(0,1)$ ) was used to identify the optimal cut-off value on the ROC curve. The PHREG procedure in SAS 8.2 software (SAS Institute, Cary, NC, USA) was used for this calculation. All tests were two-tailed, and a $p$-value $<0.05$ was considered as statistically significant.

\section{Results}

Clinicopathological profiles of patients. The clinicopathological profiles are summarized in Table I. Total 129 (81.6\%) out of 158 cases were available in this study, while other $29(18.4 \%)$ cases were excluded from the study because of discordant diagnoses $(n=16)$, poor staining quality in IF analysis $(n=10)$, or lost their squamous lesion $(n=3)$. Histologically, our samples included 18 benign squamous lesion (BSL) (average age: 68.7 years), 37 LGD (average age: 70.9 years), 22 HGD (average age: 69.0 years), and 52 OSCC (average age: 72.3 years) samples. Representative lesion images are shown in Figure 1.

53BP1 expression in oral squamous epithelial lesions. The results of IF analyses for 53BP1 expression in the oral squamous epithelial lesion are presented in Table II, and representative images are depicted in Figure 2. The histological type of oral squamous epithelial lesion was significantly associated with the 53BP1 expression type $(p<0.0001)$. In BSL samples, $74.7 \%$ of nuclei had stable expression, and only $2.6 \%$ of nuclei had HDDR- or LF-type expression. Similarly, $82.8 \%$ of nuclei in OED samples had stable expression, and only $2.7 \%$ had HDDR- or LF-type expression. In OSCC samples, $48.7 \%$ of nuclei had stable expression, and $31.4 \%$ of nuclei showed HDDR- or LF-type expression. The ratio of nuclei with 53BP1 NF amongst the counted nuclei was significantly higher in OSCC samples than in other lesions $(p<0.0001)$, whereas no significant difference was observed between BSL, and LGD and HGD OED samples. If $6.8 \%$ was adopted as the cut-off value 

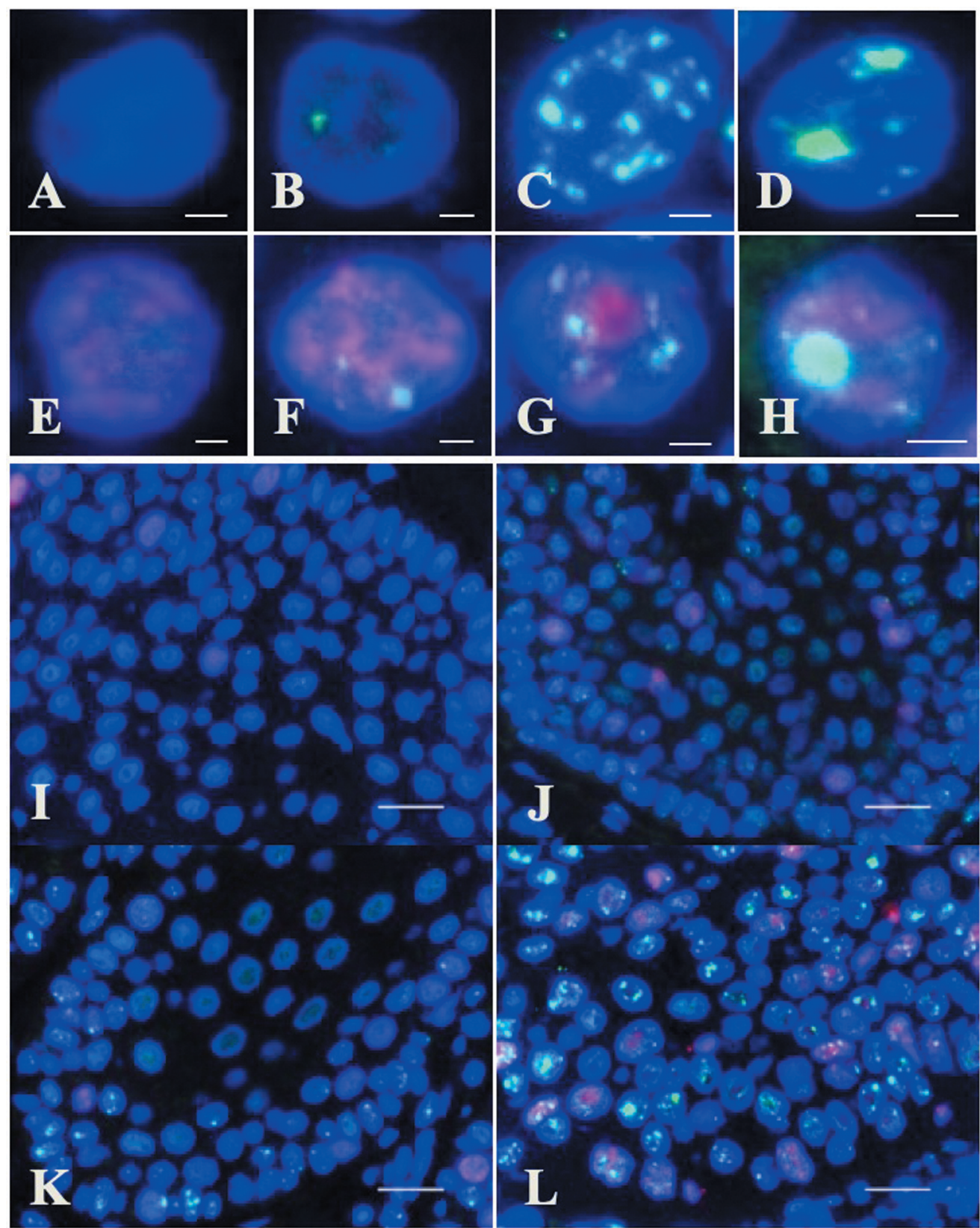

Figure 2. Dual immunofluorescence for p53-binding protein 1 (53BP1) (green) and Ki-67 (red) in oral epithelial lesions. Eight types of p53-binding protein 1 (53BP1) expression were observed by immunofluorescence using Ki-67 expression (A-H). (A and E): Stable type, no or faint nuclear 53BP1 staining. (B and F): Low DNA damage response (DDR)-type, characterized by 1 or 2 discrete 53BP1 nuclear foci. (C and G): High DDRtype, with 3 or more discrete 53BP1 nuclear foci. $(D$ and $H)$ : Large discrete nuclear foci measuring $\geq 1 \mu \mathrm{m}$. The scale bars indicate $2 \mu \mathrm{m}$. (I): Benign squamous lesion. (J): Low-grade dysplasia. (K): High-grade dysplasia. (L): Oral squamous cell carcinoma. The scale bars indicate 20 um.

[area under the curve (AUC): 0.862, distance: 0.247] for the diagnosis of HGD or OSCC, the sensitivity and specificity were $77.0 \%$ and $91.9 \%$, respectively. If $15.1 \%$ was adopted as the cut-off value (AUC: 0.983, distance: 0.108) to diagnose OSCC, the sensitivity and specificity were $94.2 \%$ and $91.0 \%$, respectively.
Among Ki-67-positive cells, HDDR- and LF-type 53BP1 expression were observed more frequently in samples with higher histological grades: $0.3 \%, 0.6 \%$, and $8.0 \%$ of nuclei in BSL, OED, and OSCC samples, respectively. If $1.1 \%$ was adopted as the cut-off value (AUC: 0.878 , distance: 0.26 ) to diagnose HGD or OSCC, the sensitivity and specificity were 
Table I. Clinicopathologic profiles of patients included in the study.

\begin{tabular}{|c|c|c|c|c|c|c|c|c|c|c|c|c|c|c|}
\hline & \multirow[t]{2}{*}{$\mathrm{n}$} & \multirow[t]{2}{*}{$\mathrm{M} / \mathrm{F}$} & \multirow{2}{*}{$\begin{array}{c}\text { Age } \\
\text { (range) }\end{array}$} & \multicolumn{5}{|c|}{ Sites } & \multicolumn{6}{|c|}{ Clinical diagnoses } \\
\hline & & & & $\mathrm{T}$ & B & G & $\mathrm{P}$ & $\mathrm{O}$ & $\begin{array}{l}\text { Lichen } \\
\text { planus }\end{array}$ & Leukoplakia & $\begin{array}{c}\text { Erosion/ } \\
\text { ulcer }\end{array}$ & Neoplasia & Carcinoma & $\mathrm{O}$ \\
\hline BSL & 18 & $9 / 9$ & $\begin{array}{c}68.7 \\
(43-86)\end{array}$ & $\begin{array}{c}1 \\
(5.6 \%)\end{array}$ & $\begin{array}{c}4 \\
(22.2 \%)\end{array}$ & $\begin{array}{c}9 \\
(50 \%)\end{array}$ & $\begin{array}{c}3 \\
(16.7 \%)\end{array}$ & $\begin{array}{c}1 \\
(5.6 \%)\end{array}$ & $\begin{array}{c}1 \\
(5.6 \%)\end{array}$ & $\begin{array}{c}4 \\
(22.2 \%)\end{array}$ & $\begin{array}{c}1 \\
(5.6 \%)\end{array}$ & $\begin{array}{c}3 \\
(16.7 \%)\end{array}$ & $\begin{array}{c}6 \\
(33.3 \%)\end{array}$ & $\begin{array}{c}3 \\
(16.7 \%)\end{array}$ \\
\hline OED & 59 & $33 / 26$ & $\begin{array}{c}70.2 \\
(35-92)\end{array}$ & $\begin{array}{c}25 \\
(42.4 \%)\end{array}$ & $\begin{array}{c}14 \\
(23.7 \%)\end{array}$ & $\begin{array}{c}17 \\
(28.8 \%)\end{array}$ & $\begin{array}{c}2 \\
(3.4 \%)\end{array}$ & $\begin{array}{c}1 \\
(1.7 \%)\end{array}$ & $\begin{array}{c}3 \\
(5.1 \%)\end{array}$ & $\begin{array}{c}44 \\
(74.6 \%)\end{array}$ & $\begin{array}{c}3 \\
(5.1 \%)\end{array}$ & $\begin{array}{c}4 \\
(6.8 \%)\end{array}$ & $\begin{array}{c}5 \\
(8.5 \%)\end{array}$ & 0 \\
\hline LGD & 37 & $21 / 16$ & $\begin{array}{c}70.9 \\
(47-92)\end{array}$ & $\begin{array}{c}14 \\
(37.8 \%)\end{array}$ & $\begin{array}{c}7 \\
(18.9 \%)\end{array}$ & $\begin{array}{c}14 \\
(37.8 \%)\end{array}$ & $\begin{array}{c}2 \\
(5.4 \%)\end{array}$ & 0 & $\begin{array}{c}3 \\
(8.1 \%)\end{array}$ & $\begin{array}{c}27 \\
(73.0 \%)\end{array}$ & $\begin{array}{c}1 \\
(2.7 \%)\end{array}$ & $\begin{array}{c}4 \\
(10.8 \%)\end{array}$ & $\begin{array}{c}2 \\
(5.4 \%)\end{array}$ & 0 \\
\hline HGD & 22 & $12 / 10$ & $\begin{array}{c}69.0 \\
(35-83)\end{array}$ & $\begin{array}{c}11 \\
(50.0 \%)\end{array}$ & $\begin{array}{c}7 \\
(31.8 \%)\end{array}$ & $\begin{array}{c}3 \\
(13.6 \%)\end{array}$ & 0 & $\begin{array}{c}1 \\
(4.5 \%)\end{array}$ & 0 & $\begin{array}{c}17 \\
(77.2 \%)\end{array}$ & $\begin{array}{c}2 \\
(9.1 \%)\end{array}$ & 0 & $\begin{array}{c}3 \\
(13.6 \%)\end{array}$ & 0 \\
\hline OSCC & 52 & $25 / 27$ & $\begin{array}{c}72.3 \\
(29-99)\end{array}$ & $\begin{array}{c}14 \\
(26.9 \%)\end{array}$ & $\begin{array}{c}11 \\
(21.2 \%)\end{array}$ & $\begin{array}{c}18 \\
(34.6 \%)\end{array}$ & $\begin{array}{c}5 \\
(9.6 \%)\end{array}$ & $\begin{array}{c}4 \\
(7.7 \%)\end{array}$ & $\begin{array}{c}2 \\
(3.8 \%)\end{array}$ & $\begin{array}{c}4 \\
(7.7 \%)\end{array}$ & $\begin{array}{c}2 \\
(3.8 \%)\end{array}$ & $\begin{array}{c}7 \\
(13.5 \%)\end{array}$ & $\begin{array}{c}34 \\
(65.4 \%)\end{array}$ & $\begin{array}{c}3 \\
(5.8 \%)\end{array}$ \\
\hline
\end{tabular}

M: Male; F: female; T: tongue; B: buccal mucosa; G: gingiva; P: palatine; O: others; BSL: benign squamous lesion; OED: oral epithelial dysplasia; LGD: low-grade dysplasia; HGD: high-grade dysplasia; OSCC: oral squamous cell carcinoma.

Table II. Types of p53-binding protein 1 (53BP1) expression in oral squamous epithelial lesions.

\begin{tabular}{|c|c|c|c|c|c|c|c|c|c|c|}
\hline & \multirow[t]{2}{*}{$\begin{array}{c}\text { Counted } \\
\text { nuclei }\end{array}$} & \multicolumn{4}{|c|}{$\begin{array}{l}\text { Type of 53BP1 expression } \\
\text { in counted nuclei }\end{array}$} & \multirow[t]{2}{*}{$\begin{array}{l}\text { Ki-67-positive } \\
\text { nuclei }\end{array}$} & \multicolumn{4}{|c|}{$\begin{array}{l}\text { Type of 53BP1 expression in } \\
\text { Ki-67-positive nuclei }\end{array}$} \\
\hline & & Stable & LDDR & HDDR & $\mathrm{LF}$ & & Stable & LDDR & HDDR & $\mathrm{LF}$ \\
\hline BSL & 10,121 & $\begin{array}{c}7,558 \\
(74.7 \%)\end{array}$ & $\begin{array}{c}2,303 \\
(22.8 \%)\end{array}$ & $\begin{array}{c}244 \\
(2.4 \%)\end{array}$ & $\begin{array}{c}16 \\
(0.2 \%)\end{array}$ & $\begin{array}{c}1,512 \\
(14.9 \%)\end{array}$ & $\begin{array}{c}1,224 \\
(12.1 \%)\end{array}$ & $\begin{array}{c}257 \\
(2.5 \%)\end{array}$ & $\begin{array}{c}31 \\
(0.3 \%)\end{array}$ & $\begin{array}{c}0 \\
(0.0 \%)\end{array}$ \\
\hline OED & 37,434 & $\begin{array}{c}31,013 \\
(82.8 \%)\end{array}$ & $\begin{array}{c}5,379 \\
(14.4 \%)\end{array}$ & $\begin{array}{c}875 \\
(2.3 \%)\end{array}$ & $\begin{array}{c}167 \\
(0.4 \%)\end{array}$ & $\begin{array}{c}4.241 \\
(11.3 \%)\end{array}$ & $\begin{array}{c}3,271 \\
(8.7 \%)\end{array}$ & $\begin{array}{c}761 \\
(2.0 \%)\end{array}$ & $\begin{array}{c}185 \\
(0.5 \%)\end{array}$ & $\begin{array}{c}25 \\
(0.1 \%)\end{array}$ \\
\hline LGD & 20,312 & $\begin{array}{c}16,490 \\
(81.2 \%)\end{array}$ & $\begin{array}{c}3,317 \\
(16.3 \%)\end{array}$ & $\begin{array}{c}456 \\
(2.2 \%)\end{array}$ & $\begin{array}{c}49 \\
(0.2 \%)\end{array}$ & $\begin{array}{l}2,011 \\
(9.9 \%)\end{array}$ & $\begin{array}{c}1,562 \\
(7.7 \%)\end{array}$ & $\begin{array}{c}389 \\
(1.9 \%)\end{array}$ & $\begin{array}{c}58 \\
(0.3 \%)\end{array}$ & $\begin{array}{c}2 \\
(0.0 \%)\end{array}$ \\
\hline HGD & 17,122 & $\begin{array}{l}14,523 \\
(84.8 \%)\end{array}$ & $\begin{array}{l}2,062 \\
(12.0 \%)\end{array}$ & $\begin{array}{c}419 \\
(2.4 \%)\end{array}$ & $\begin{array}{l}118 \\
(0.7 \%)\end{array}$ & $\begin{array}{c}2,231 \\
(13.0 \%)\end{array}$ & $\begin{array}{l}1,709 \\
(10.0 \%)\end{array}$ & $\begin{array}{c}372 \\
(2.2 \%)\end{array}$ & $\begin{array}{c}127 \\
(0.7 \%)\end{array}$ & $\begin{array}{c}23 \\
(0.1 \%)\end{array}$ \\
\hline OSCC & 32,283 & $\begin{array}{c}15,731 \\
(48.7 \%)\end{array}$ & $\begin{array}{c}6,422 \\
(19.9 \%)\end{array}$ & $\begin{array}{c}9,270 \\
(28.7 \%)\end{array}$ & $\begin{array}{c}860 \\
(2.7 \%)\end{array}$ & $\begin{array}{c}7,192 \\
(22.3 \%)\end{array}$ & $\begin{array}{c}3,297 \\
(10.2 \%)\end{array}$ & $\begin{array}{l}1,316 \\
(4.1 \%)\end{array}$ & $\begin{array}{c}2,472 \\
(7.7 \%)\end{array}$ & $\begin{array}{c}107 \\
(0.3 \%)\end{array}$ \\
\hline & \multicolumn{6}{|c|}{$p<0.0001^{*}$} & \multicolumn{4}{|c|}{$p<0.0001 *$} \\
\hline
\end{tabular}

LDDR: Low DNA damage response; HDDR: high DNA damage response; LF: large foci; BSL: benign squamous lesion; OED: oral epithelial dysplasia; LGD: low-grade dysplasia; HGD: high-grade dysplasia; OSCC: oral squamous cell carcinoma.*by Jonckheere-Tepstra test.

$75.7 \%$ and $91.9 \%$, respectively. Finally, if $2.6 \%$ was adopted as the cut-off value (AUC: 0.931, distance: 0.108 ) to diagnose OSCC, the sensitivity and specificity were $94.2 \%$ and $91.0 \%$, respectively.

Immunoreactivity of $p 53$ and $p 16^{I N K 4 a}$ expression in oral squamous epithelial lesions. The IHC results for p53 and p16 ${ }^{\mathrm{INK} 4 \mathrm{a}}$ expression in oral squamous epithelial lesions are presented in Table III, and representative images are depicted in Figure 3. The percentage of cases with p53 immunoreactivity was significantly higher in samples of higher histological grade: $5.6 \%, 6.8 \%$, and $28.8 \%$ in BSL, OED, and OSCC cases, respectively. Conversely, p16 ${ }^{\text {INK4a }}$ immunoreactivity was significantly lower in samples of
Table III. Immunohistochemical results for $p 53$ and p16 ${ }^{I N K 4 a}$ expression in oral squamous epithelial lesions.

\begin{tabular}{lcccc}
\hline & $\mathrm{n}$ & $\mathrm{p} 53$ positive & \multicolumn{2}{c}{$\mathrm{p} 16^{\mathrm{INK} 4 \mathrm{a}}$ positive } \\
\cline { 3 - 5 } & & & Diffuse & Focal \\
\hline BSL & 18 & $1(5.6 \%)$ & $6(33.3 \%)$ & $10(55.6 \%)$ \\
OED & 59 & $4(6.8 \%)$ & $10(16.9 \%)$ & $31(52.5 \%)$ \\
LGD & 37 & $1(2.7 \%)$ & $10(27.0 \%)$ & $20(54.1 \%)$ \\
HGD & 22 & $3(13.6 \%)$ & 0 & $11(50.0 \%)$ \\
OSCC & 52 & $15(28.8 \%)$ & $10(19.2 \%)$ & $11(21.2 \%)$ \\
& & $p=0.0009 *$ & $p=0.5223 *$ & $p=0.0004 *$ \\
\hline
\end{tabular}

BSL: Benign squamous lesion; OED: oral epithelial dysplasia; LGD: low-grade dysplasia; HGD: high-grade dysplasia; OSCC: oral squamous cell carcinoma. *By Cochran-Armitage test. 

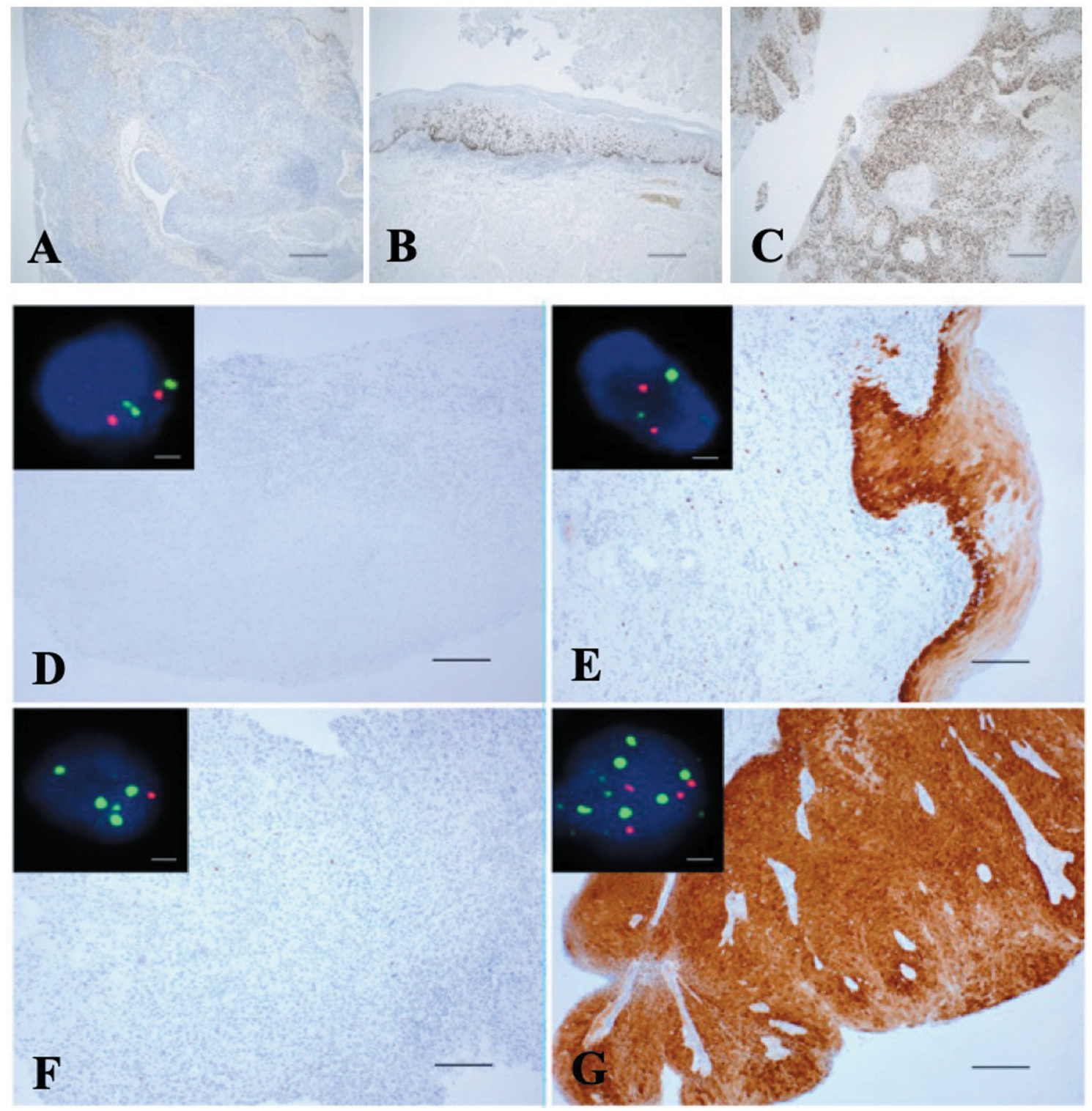

Figure 3. Immunohistochemistry analysis for p53 expression in oral squamous epithelial lesions (A-C), and comparison between immunohistochemical p16INK4a expression and presence of the 9q21 locus (orange) by dual-color fluorescence in situ hybridization (FISH) using the CEP9 probe (green) in oral squamous epithelial lesions $(D-G)$. (A): Benign squamous lesion. (B): Oral epithelial dysplasia. (C): Oral squamous cell carcinoma. ( $D$ and $E$ ): Two cases of benign squamous lesions had a wild type 9p21 locus (orange/green=1) regardless of p16INK4a immunoreactivity. ( $F$ and $G$ ): Two cases of oral squamous cell carcinoma exhibited loss of the 9p21 locus (orange/green $<0.5$ ) regardless of p16 ${ }^{\prime N K} 4$ a immunoreactivity. The scale bars indicate $400 \mu \mathrm{m}$ for immunohistochemical p53 and p16INK4a expressions and $2 \mu \mathrm{m}$ for FISH analysis.

higher histological grade: $88.9 \%, 69.4 \%$, and $40.3 \%$ in BSL, OED, and OSCC cases, respectively.

FISH analysis of the 9p21 locus in oral squamous epithelial lesions. Representative FISH images for the $9 p 21$ locus in oral squamous epithelial lesions are depicted along with $\mathrm{p} 16^{\mathrm{INK} 4 \mathrm{a}}$ immunoreactivity in Figure 3 to facilitate comparison in the respective cases. The average number of nuclei exhibiting loss of the $9 p 21$ locus ( $9 p 21$ [orange]-to-CEP9 [green] signal ratio $<0.5$ is shown in Table IV. The results are shown in comparison to $\mathrm{p} 16^{\mathrm{INK} 4 \mathrm{a}}$ immunoreactivity in BSL and OSCC samples. Loss of the $9 p 21$ locus was significantly more common in OSCC samples than BSL samples, however it was not associated with $\mathrm{p} 16^{\mathrm{INK} 4 \mathrm{a}}$ immunoreactivity. 
Table IV. Comparison between p16 INK4a immunoreactivity and chromosome $9 q 21$ alteration by dual-color FISH for in oral squamous epithelial lesions.

\begin{tabular}{lccc}
\hline Type & $\mathrm{n}$ & $\mathrm{p} 16^{\mathrm{INK} 4 \mathrm{a}}$ & $\begin{array}{c}\text { Average ratio of nuclei with } \\
\text { loss of } 9 p 21 \text { per case by FISH }\end{array}$ \\
\hline BSL & 2 & - & $49.5 \% * \uparrow$ \\
& 3 & $2+$ & $53.0 \% * \uparrow$ \\
OSCC & 5 & - & $84.6 \% \uparrow$ \\
& 5 & $2+$ & $81.2 \%$ \\
\hline
\end{tabular}

FISH: Fluorescence in situ hybridization; BSL: benign squamous lesion; OSCC: oral squamous cell carcinoma. $\uparrow p<0.0001, * p=0.6914$, $* * p=0.2010$ by $t$-test.

\section{Discussion}

We observed a higher frequency of 53BP1 NF in HGD and OSCC samples than in BSL and LGD, and in the OSCC compared to the OED samples, in biopsied oral squamous epithelial lesions. These findings suggest that endogenous DNA DSBs activate DDR in higher-grade lesions, contributing to histological disturbance and malignant transformation. We hypothesized that the co-localization of 53BP1 NF and Ki-67 expression in the nucleus is an abnormal DDR phenotype, because DDR is normally activated during cell-cycle arrest $(11,12)$. Our results reveal frequent co-localization of 53BP1 NF and Ki-67 expression in OSCC cell nuclei, suggesting perturbed DDR in cancer cells. Impairment of the DDR machinery is frequently seen in several human cancers, and it induces genomic instability, a hallmark of malignancy. Thus, we believe that analyzing 53BP1 expression by IF can be useful for estimation of the level of genomic instability and malignant potential of human tumors. Indeed, our previous reports have demonstrated that the type of 53BP1 expression is significantly associated with the malignant potency of several tumors $(13,14)$.

Regarding oral epithelial lesions, other authors suggested that a high level of 53BP1 immunoreactivity was associated with a risk of oral lichen planus neoplastic transformation (15). Furthermore, in a Fanconi anemia (FA) patient suffering relapsing OSCC, the defective DNA repair was detected in tissue specimens of skin, oral mucosa and tumor with an excess of unrepaired DSBs in the proliferating zone by analyzing DDR proteins, including 53BP1 (16). FA is molecular pathologically characterized by cellular hypersensitivity to DNA damaging agents that induce DNA interstrand crosslinking, impairing strand separation and unwinding, and ultimately hindering replication and transcription, therefore, is associated with an increased predisposition to not only hematologic but also nonhematologic tumors, particularly SSC of the aerodigestive and anogenital tract (17). Because this study also showed that the 53BP1 NF analysis of irradiated blood lymphocytes allowed to identify patients with an impaired DSB repair capacity, defective function of 53BP1 molecule may play a significant pathological role in malignant transformation of OED. Interestingly, a recent evidence suggested that poly (adenosine diphosphate-ribose) polymerase (PARP) inhibitor olaparib, which causes an accumulation of DNA damage and tumor-cell death by preventing DDR machinery, potentiates anticancer drug cytotoxicity via 53BP1 in esophageal SCC cells (18). Thus, 53BP1 can be an attractive candidate of molecular-targeted therapy for SCC in aerodigestive tract.

Histopathological OED grading by biopsy is the gold standard for determining a management approach (19-21). The degree of dysplasia is reportedly an independent marker for the prediction of malignant transformation, as HGD samples are associated with a 2.78-fold higher risk of progression to cancer than LGD samples (22). Importantly, our results indicate that IF-based analysis of 53BP1 expression is an outstanding diagnostic test to distinguish OSCC from OED or BSL, and HGD from LGD or BSL, according to a statistic textbook (23). However, the clinical application of this test is limited by the need for a fluorescence microscope and training to evaluate the staining results, which requires an understanding of the morphological features.

No single biomarker can stratify the cancer risk associated with OED. We found that p53 immunopositivity was significantly higher in OSCC than in OED and BSL samples, however, only $28.8 \%$ of OSCC cases were positive, indicating that impairment of p53 tumor suppressor function is not the main pathway in oral carcinogenesis. IHC revealed a stepwise decrease in $\mathrm{p} 16^{\mathrm{INK} 4 \mathrm{a}}$ expression with oral carcinogenesis progression. Immunohistochemical $\mathrm{p} 16^{\mathrm{INK} 4 \mathrm{a}}$ expression is a surrogate marker of HPV infection, and $\mathrm{p} 16^{\mathrm{INK} 4 \mathrm{a}} \mathrm{IHC}$ is an auxiliary technique for diagnosis of uterine cervical SIL. We inferred that 53BP1 expression pattern is a valuable biomarker for identifying the grade of cervical lesions caused by the integration of HR-HPV into the host genome (10). However, in oral lesions, up to one-third of OSCC cases are $\mathrm{p} 16^{\mathrm{INK} 4 \mathrm{I}_{-}}$ positive, and viral DNA is detectable by polymerase chain reaction in about $28 \%$ cases $(24,25)$. ISH, a more sensitive method of detecting HR-HPV, revealed very few positive cases $(1-10 \%)(26,27)$, suggesting a low incidence of HPVdriven OSCC. Therefore, $\mathrm{p} 16^{\mathrm{INK} 4 \mathrm{a}}$ immunoreactivity is not concordant with HPV infection or dysplasia grade in the oral cavity, unlike in the uterine cervix. In addition, the current study demonstrates that reduced $\mathrm{p} 16^{\mathrm{INK} 4 \mathrm{a}}$ levels are not associated with loss of the $9 p 21$ locus in oral lesions, which is a critical early event during carcinogenesis $(28,29)$. Thus, $\mathrm{p} 16^{\mathrm{INK} 4 \mathrm{a}}$ expression level is not a marker of the malignant transformation of oral lesions. Expression of $\mathrm{p} 16^{\mathrm{INK} 4 \mathrm{a}}$ in BSL represents a response to growth stress caused by various 
stimuli, including inflammatory factors (30), suggesting that molecular cell-cycle regulation mechanisms are intact in benign lesions. In this study, 53BP1 NF were observed in $25.4 \%$ of BSL cases, although HDDR- and LF-type 53BP1 were rare. Similarly, our previous study on the esophagus revealed more 53BP1 NF in non-neoplastic epithelium than in neoplastic lesions. OSCC is typically associated with risk factors such as tobacco use, alcohol consumption, and betel quid chewing $(31,32)$. As the normal oral and esophageal squamous epitheliums are continually exposed to genotoxic agents in food, beverages, and tobacco, DDR-type 53BP1 immunoreactivity in the non-neoplastic epithelium may represent a minor genotoxic injury induced by external factors.

We propose that 53BP1 expression can be a valuable biomarker to estimate the endogenously occurring DNA DSBs or altered DDR in oral squamous epithelial lesion. The type of 53BP1 expression was associated with grade of OED, thereby influencing clinical management. Further studies are required to confirm the utility of IF analysis of 53BP1 expression as an auxiliary histologic technique to diagnose OED.

\section{Conflicts of Interest}

The Authors declare no competing interests.

\section{Authors' Contributions}

T.I., K.M., and M.N. designed and performed experiments, and wrote the article; K.T., N.U., C.O., Y.M., and Y.A. gave technical support and conceptual advice; H.K. performed statistical analyses. H.K., S.M., and M.N. confirmed pathological diagnoses. M.N. reviewed and revised the manuscript.

\section{Acknowledgements}

This work was supported in part by the Atomic Bomb Disease Institute (Nagasaki University) and is a Joint Research by Hiroshima University, Nagasaki University, and Fukushima Medical University Research Base for Radiation Accidents and Medical Science. We wish to thank Editage (www.editage.jp) for English language editing.

\section{References}

1 Lu YC, Chen YJ, Wang HM, Tsai CY, Chen WH, Huang YC, Fan KH, Tsai CN, Huang SF, Kang CJ, Chang JT and Cheng AJ: Oncogenic function and early detection potential of miRNA-10b in oral cancer as identified by microRNA profiling. Cancer Prev Res (Phila) 5(4): 665-674, 2012. PMID: 22318752. DOI: 10.1158/1940-6207.CAPR-11-0358

2 Warnakulasuriya S: Causes of oral cancer - an appraisal of controversies. Br Dent J 207(10): 471-475, 2009. PMID: 19946320. DOI: $10.1038 /$ sj.bdj.2009.1009

3 El-Naggar AK, Chan JKC, Grandis JR, Takata T and Slootweg PJ: WHO Classification of Head and Neck Tumours WHO/IARC
Classification of Tumours, 4th ed., IARC Publications, Lyon, France, 2017.

4 Japanese Society of Oral Oncology: General Rules for Clinical and Pathological Studies on Oral Cancer, 2nd ed., Tokyo Kanehara \& Co., Ltd., Tokyo, Japan (in Japanese), 2019.

5 Mehanna HM, Rattay T, Smith J and McConkey CC: Treatment and follow-up of oral dysplasia - a systematic review and metaanalysis. Head Neck 31(12): 1600-1609, 2009. PMID: 19455705. DOI: $10.1002 /$ hed.21131

6 Joo WS, Jeffrey PD, Cantor SB, Finnin MS, Livingston DM and Pavletich NP: Structure of the 53BP1 BRCT region bound to p53 and its comparison to the Brca1 BRCT structure. Genes Dev 16(5): 583-593, 2002. PMID: 11877378. DOI: 10.1101/ $\operatorname{gad} .959202$

7 Anderson L, Henderson C and Adachi Y: Phosphorylation and rapid relocalization of 53BP1 to nuclear foci upon DNA damage. Mol Cell Biol 21(5): 1719-1729, 2001. PMID: 11238909. DOI: 10.1128/MCB.21.5.1719-1729.2001

8 Ward IM, Minn K, Jorda KG and Chen J: Accumulation of checkpoint protein 53BP1 at DNA breaks involves its binding to phosphorylated histone H2AX. J Biol Chem 278(22): 1957919582, 2003. PMID: 12697768. DOI: 10.1074/jbc.C300117200

9 Otsubo R, Matsuda K, Mussazhanova Z, Sato A, Matsumoto M, Yano H, Oikawa M, Kondo H, Ito M, Miyauchi A, Hirokawa M, Nagayasu T and Nakashima M: A novel diagnostic method for thyroid follicular tumors based on immunofluorescence analysis of p53-binding protein 1 expression: Detection of genomic instability. Thyroid 29(5): 657-665, 2019. PMID: 30929573. DOI: $10.1089 /$ thy.2018.0548

10 Matsuda K, Miura S, Kurashige T, Suzuki K, Kondo H, Ihara M, Nakajima H, Masuzaki H and Nakashima M: Significance of p53-binding protein 1 nuclear foci in uterine cervical lesions: endogenous DNA double strand breaks and genomic instability during carcinogenesis. Histopathology 59(3): 441-451, 2011. PMID: 22034884. DOI: 10.1111/j.1365-2559.2011.03963.x

11 Dunton CJ, van Hoeven KH, Kovatich AJ, Oliver RE, Scacheri RQ, Cater JR and Carlson JA Jr: Ki-67 antigen staining as an adjunct to identifying cervical intraepithelial neoplasia. Gynecol Oncol 64(3): 451-455, 1997. PMID: 9062149. DOI: 10.1006/ gyno.1996.4602

12 Cuylen S, Blaukopf C, Politi AZ, Müller-Reichert T, Neumann B, Poser I, Ellenberg J, Hyman AA and Gerlich DW: Ki-67 acts as a biological surfactant to disperse mitotic chromosomes. Nature 535(7611): 308-312, 2016. PMID: 27362226. DOI: 10.1038 /nature 18610

13 Matsuda K, Kawasaki T, Akazawa Y, Hasegawa Y, Kondo H, Suzuki K, Iseki M and Nakashima M: Expression pattern of p53-binding protein 1 as a new molecular indicator of genomic instability in bladder urothelial carcinoma. Sci Rep 8(1): 15477, 2018. PMID: 30341375. DOI: 10.1038/s41598-018-33761-9

14 Ueki N, Akazawa Y, Miura S, Matsuda K, Kurohama H, Imaizumi T, Kondo $\mathrm{H}$ and Nakashima M: Significant association between 53 BP1 expression and grade of intraepithelial neoplasia of esophagus: Alteration during esophageal carcinogenesis. Pathol Res Pract 215(11): 152601, 2019. PMID: 31570283. DOI: $10.1016 /$ j.prp.2019.152601

15 Squarzanti DF, Cena T, Sorrentino R, Migliario M, Chiocchetti A, Rimondini L, Azzimonti B and Valente G: Implications on pathogenesis and risk of oral lichen planus neoplastic transformation: an ex-vivo retrospective immunohistochemical 
study. Histol Histopathol 34(9): 1015-1024, 2019. PMID: 30907426. DOI: $10.14670 / \mathrm{HH}-18-104$

16 Schuler N, Palm J, Kaiser M, Betten D, Furtwängler R, Rübe C, Graf $\mathrm{N}$ and Rübe CE: DNA-damage foci to detect and characterize DNA repair alterations in children treated for pediatric malignancies. PLoS One 9(3): e91319, 2014. PMID: 24637877. DOI: 10.1371/journal.pone.0091319

17 Kutler DI, Auerbach AD, Satagopan J, Giampietro PF, Batish SD, Huvos AG, Goberdhan A, Shah JP and Singh B: High incidence of head and neck squamous cell carcinoma in patients with Fanconi anemia. Arch Otolaryngol Head Neck Surg 129(1): 106112, 2003. PMID: 12525204. DOI: 10.1001/archotol.129.1.106

18 Miyamoto K, Minegaki T, Hirano S, Hayashi I, Tsujimoto M and Nishiguchi K: Olaparib potentiates anticancer drug cytotoxicity via 53BP1 in oesophageal squamous cell carcinoma cells. Anticancer Res 40(2): 813-823, 2020. PMID: 32014924. DOI: 10.21873/anticanres.14013

19 Napier SS and Speight PM: Natural history of potentially malignant oral lesions and conditions: an overview of the literature. J Oral Pathol Med 37(1): 1-10, 2008. PMID: 18154571. DOI: 10.1111/j.1600-0714.2007.00579.x

20 van der Waal I: Potentially malignant disorders of the oral and oropharyngeal mucosa; terminology, classification and present concepts of management. Oral Oncol 45(4-5): 317-323, 2009. PMID: 18674954. DOI: 10.1016/j.oraloncology.2008.05.016

21 van der Waal I: Oral potentially malignant disorders: is malignant transformation predictable and preventable? Med Oral Patol Oral Cir Bucal 19(4): e386-e390, 2014. PMID: 24905952. DOI: $10.4317 /$ medoral.20205

22 Liu W, Bao ZX, Shi LJ, Tang GY and Zhou ZT: Malignant transformation of oral epithelial dysplasia: clinicopathological risk factors and outcome analysis in a retrospective cohort of 138 cases. Histopathology 59(4): 733-740, 2011. PMID: 21916948. DOI: 10.1111/j.1365-2559.2011.03938.x

23 Hosmer DW and Lemeshow S: Applied Logistic Regression, 2nd ed., John Wiley \& Sons, Inc., New York, NY, USA, 2000.

24 Reuschenbach M, Kansy K, Garbe K, Vinokurova S, Flechtenmacher C, Toth C, Prigge ES, Thiele OC, Reinert S, Hoffmann J, von Knebel Doeberitz M and Freier K: Lack of evidence of human papillomavirus-induced squamous cell carcinomas of the oral cavity in southern Germany. Oral Oncol 49(9): 937-942, 2013. PMID: 23608471. DOI: 10.1016/ j.oraloncology.2013.03.451

25 Zafereo ME, Xu L, Dahlstrom KR, Viamonte CA, El-Naggar AK, Wei Q, Li G and Sturgis EM: Squamous cell carcinoma of the oral cavity often overexpresses p16 but is rarely driven by human papillomavirus. Oral Oncol 56: 47-53, 2016. PMID: 27086486. DOI: 10.1016/j.oraloncology.2016.03.003
26 Gillison ML, Chaturvedi AK, Anderson WF and Fakhry C: Epidemiology of human papillomavirus-positive head and neck squamous cell carcinoma. J Clin Oncol 33(29): 3235-3242, 2015. PMID: 26351338. DOI: 10.1200/JCO.2015.61.6995

27 Sgaramella N, Coates PJ, Strindlund K, Loljung L, Colella G, Laurell G, Rossiello R, Muzio LL, Loizou C, Tartaro G, Olofsson K, Danielsson K, Fåhraeus R and Nylander K: Expression of p16 in squamous cell carcinoma of the mobile tongue is independent of HPV infection despite presence of the HPV-receptor syndecan-1. Br J Cancer 113(2): 321-326, 2015. PMID: 26057450. DOI: 10.1038/bjc.2015.207

28 Jones TD, Zhang S, Lopez-Beltran A, Eble JN, Sung MT, MacLennan GT, Montironi R, Tan PH, Zheng S, Baldridge LA and Cheng L: Urothelial carcinoma with an inverted growth pattern can be distinguished from inverted papilloma by fluorescence in situ hybridization, immunohistochemistry, and morphologic analysis. Am J Surg Pathol 31(12): 1861-1867, 2007. PMID: 18043040. DOI: 10.1097/PAS .0b013e318060cb9d

29 Zhang $X$ and Zhang Y: Bladder cancer and genetic mutations. Cell Biochem Biophys 73(1): 65-69, 2015. PMID: 27352265. DOI: $10.1007 / \mathrm{s} 12013-015-0574-\mathrm{z}$

30 Alexander RE, Davidson DD, Lopez-Beltran A, Montironi R, MacLennan GT, Compérat E, Idrees MT, Emerson RE and Cheng L: Human papillomavirus is not an etiologic agent of urothelial inverted papillomas. Am J Surg Pathol 37(8): 1223-1228, 2013. PMID: 23681080. DOI: 10.1097/PAS.0b013e3182863fc 1

31 Lee CH, Ko AM, Warnakulasuriya S, Yin BL, Sunarjo, Zain RB, Ibrahim SO, Liu ZW, Li WH, Zhang SS, Kuntoro, Utomo B, Rajapakse PS, Warusavithana SA, Razak IA, Abdullah N, Shrestha P, Kwan AL, Shieh TY, Chen MK and Ko YC: Intercountry prevalences and practices of betel-quid use in south, southeast and eastern Asia regions and associated oral preneoplastic disorders: an international collaborative study by Asian betel-quid consortium of south and east Asia. Int J Cancer 129(7): 1741-1751, 2011. PMID: 21128235. DOI: $10.1002 /$ ijc. 25809

32 Leemans CR, Braakhuis BJ and Brakenhoff RH: The molecular biology of head and neck cancer. Nat Rev Cancer 11(1): 9-22, 2011. PMID: 21160525. DOI: $10.1038 / \operatorname{nrc} 2982$
Received June 27, 2021

Revised July 24, 2021 Accepted August 24, 2021 